\title{
Active Space of Pheromone Plume and its Relationship to Effective Attraction Radius in Applied Models
}

\author{
John A. Byers
}

Received: 19 December 2007 / Accepted: 30 May 2008 / Published online: 27 June 2008

(C) Springer Science+Business Media, LLC 2008

\begin{abstract}
The release rate of a semiochemical lure that attracts flying insects has a specific effective attraction radius (EAR) that corresponds to the lure's orientation response strength. EAR is defined as the radius of a passive sphere that intercepts the same number of insects as a semiochemical-baited trap. It is estimated by calculating the ratio of trap catches in the field in baited and unbaited traps and the interception area of the unbaited trap. EAR serves as a standardized method for comparing the attractive strengths of lures that is independent of population density. In two-dimensional encounter rate models that are used to describe insect mass trapping and mating disruption, a circular EAR $\left(\mathrm{EAR}_{\mathrm{c}}\right)$ describes a key parameter that affects catch or influence by pheromone in the models. However, the spherical EAR, as measured in the field, should be transformed to an $\mathrm{EAR}_{\mathrm{c}}$ for appropriate predictions in such models. The $\mathrm{EAR}_{\mathrm{c}}$ is calculated as $\left(\pi / 2 \mathrm{EAR}^{2}\right) / F_{\mathrm{L}}$, where $F_{\mathrm{L}}$ is the effective thickness of the flight layer where the insect searches. $F_{\mathrm{L}}$ was estimated from catches of insects (42 species in the orders Coleoptera, Lepidoptera, Diptera, Hemiptera, and Thysanoptera) on traps at various heights as reported in the literature. The $\mathrm{EAR}_{\mathrm{c}}$ was proposed further as a simple but equivalent alternative to simulations of highly complex active-space plumes with variable response surfaces that have proven exceedingly difficult to quantify in nature. This hypothesis was explored in simulations where flying insects, represented as coordinate points, moved about in a correlated random walk in an area that contained a pheromone plume, represented as a sector of
\end{abstract}

\section{J. A. Byers $(\triangle)$}

US Arid-Land Agricultural Research Center, USDA-ARS,

21881 North Cardon Lane,

Maricopa, AZ, 85238, USA

e-mail: John.Byers@ARS.USDA.GOV active space composed of a capture probability surface of variable complexity. In this plume model, catch was monitored at a constant density of flying insects and then compared to simulations in which a circular $\mathrm{EAR}_{\mathrm{c}}$ was enlarged until an equivalent rate was caught. This demonstrated that there is a circular $\mathrm{EAR}_{c}$, where all insects that enter are caught, which corresponds in catch effect to any plume. Thus, the $\mathrm{EAR}_{\mathrm{c}}$, based on the field-observed EAR, can be used in encounter rate models to develop effective control programs based on mass trapping and/or mating disruption.

Keywords Computer simulation model . Integrated pest management $\cdot$ Mass trapping . Mating disruption $\cdot$ Moth pheromones $\cdot$ Pheromone plumes

\section{Introduction}

An understanding of odor dispersion in relation to behavioral responses of insects has aided in efficient development of mating disruption and mass trapping methods for control of pests (Shorey 1977; Bartell 1982; Cardé 1990; Cardé and Minks 1995; El-Sayed et al. 2006; Miller et al. 2006a, b; Byers 2007). In the past, most tests of mating disruption and mass trapping have chosen dispenser baits of various strengths and densities on an empirical basis because of the complexity of these systems. Simulation models based on individual movements of insects (Turchin 1998) might aid our understanding of mating disruption and mass trapping to optimize bait strength and distribution (Byers 2007). Worner (1991) suggests that the goals of models are to define problems, organize thoughts, understand systems, identify areas of investigation, communicate understanding, make predictions, generate hy- 
potheses, and act as standards for comparison. Models of mating disruption and mass trapping may need to consider parameters such as (a) odor dispersion (e.g., plume structure, emission rates, meteorology, and densities of chemical dispensers), (b) behavior (e.g., orientation mechanisms, sensitivity to components, mating, and dispersal), and (c) population ecology (e.g., duration, percentage mating or trapped, densities of males and females).

One parameter that could be used in models described above is the active space, defined by Elkinton and Cardé (1984) as the volume of air inside in which the odor concentration is above the threshold that elicits a behavioral reaction in the receiving organism (Sower et al. 1971; Nakamura and Kawasaki 1977; Baker and Roelofs 1981). This concept is based on various Gaussian equations that calculate the odor concentrations in still and moving air (Sutton 1953; Bossert and Wilson 1963; Fares et al. 1980). The active space has been investigated in several studies by observing wing-fanning of male moths in cages at various points within a pheromone plume (Elkinton and Cardé 1984; Elkinton et al. 1984). The fine structure of pheromone plumes on a small time scale is extremely complicated but thought to comprise filaments of higher concentrations due to turbulent eddies of air (Mankin et al. 1980; Elkinton and Cardé 1984; Baker et al. 1998).

While plumes and active spaces are three-dimensional in nature, they can be simplified further to two dimensions for practical purposes. This is because mate- and hostseeking insects disperse and orient over hundreds of meters within a relatively thin layer of air a few meters thick, as shown in many studies (e.g., Meyerdirk and Moreno 1984; Meyerdirk and Oldfield 1985; Chandler 1985; Meyer and Colvin 1985; Stone 1986; Byers et al. 1989; Stewart and Gaylor 1991; Isaacs and Byrne 1998; Pearsall and Myers 2001; Weber et al. 2005). Thinking in a two-dimensional way (Fig. 1a), the active space can be thought of as an instantaneous snapshot or as a timeaveraged area (Sutton 1953; Bossert and Wilson 1963; Elkinton and Cardé 1984; Elkinton et al. 1984; Byers 1987). Elkinton and Cardé (1984) reviewed reports that suggested that the plume's active space is affected by wind speed, turbulence, temperature, topography, vegetation, and time scale. Thus, under field conditions, the active space might be at least as chaotic as suggested in Fig. 1a.

Another concept connected to the active space is the capture probability (CP). There is likely a specific $\mathrm{CP}$ at any position in the active space that depends on the semiochemical concentration and orientation ability of the insect species (McClendon et al. 1976; Wall and Perry 1987; Branco et al. 2006). It is well known from theoretical and experimental studies above and others that concentrations of odor decline with distance from the source. In addition, it is known that at lower release rates, insects are less attracted. This is probably due to a combination of individual variation in response threshold, less receptor firing frequency, and lower plume filament flux frequency at these low concentrations (Baker et al. 1998). Therefore, we expect that insects that enter the active space of a plume at a position far from the source would have a lower probability of finding the source than an insect that enters much nearer the source. For example, McClendon et al. (1976) presented a capture probability response surface based on catch of marked boll weevils, Anthonomus grandis Boheman, released at various distances from a synthetic pheromone source. The probabilities ranged from $5 \%$ at about $150 \mathrm{~m}$ from the source to about $45 \%$ near the source. Branco et al. (2006) proposed a declining logistic function to predict capture probability with distance for scale insects that respond to sex pheromone.

The CP does not depend solely on pheromone concentration since even if the concentration is the same at two points downwind, one further than the other from the source, the insect entering farther from the source will likely have a lower $\mathrm{CP}$ due to more time needed to fly to the source and more possibilities of becoming disoriented. Thus, the CP depends on where the insect enters the active space (Fig. 1b). If the semiochemical release rate is increased, it is apparent that the active space increases in area as well as the varied $\mathrm{CP}$ values, all of which would be impractical to measure. The semiochemical release rate can be increased to a point that adaptation or confusion occurs with little catch (Bartell and Roelofs 1973; Baker and Roelofs 1981; Kuenen and Baker 1981; Baker et al. 1989; Rumbo and Vickers 1997; Judd et al. 2005). In this case, the active space should move a distance downwind from

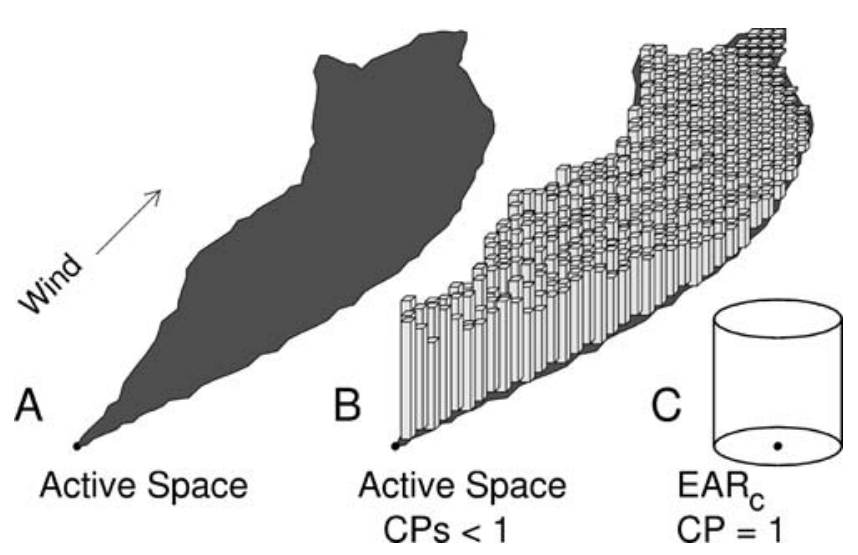

Fig. 1 a Representation of a pheromone plume as an active space in which semiochemical concentration is above a behavioral threshold eliciting orientation; b the same plume represented with $\mathrm{CP}<1$ indicating the probability of an insect reaching the pheromone source upon initial observation at a particular position; $\mathbf{c}$ the capture finding probability surface compressed into an effective attraction radius with the same effect on catch by reducing the diameter but maximizing the $\mathrm{CP}$ at a probability of 1 
the source, although it may be of similar size, while $\mathrm{CP}$ values would be drastically reduced.

The effective attraction radius (EAR) was proposed by Byers et al. (1989) as the radius of a passive sphere that would intercept the same number of insects as does a specific attractive trap baited with semiochemicals. A similar concept used in models of mate finding, mass trapping, and host-tree finding (Byers 1991, 1993a, b, 1996a, 1999) is here termed the $\mathrm{EAR}_{\mathrm{c}}$ (c for circle) to distinguish it from the spherical EAR. As discussed below, the EAR $\mathrm{c}_{\mathrm{c}}$ concept is more useful in developing practical control with mating disruption and mass trapping than the better-known active space concept. The two ideas are related. In the $\mathrm{EAR}_{\mathrm{c}}$ used in models, the $\mathrm{CP}$ response volume within the active space is compressed into a cylindrical volume with $\mathrm{CP}$ equal to 1 so that insects entering will find the source and be trapped (Fig. 1c). The cylinder can be further compressed to two dimensions so that the $\mathrm{EAR}_{\mathrm{c}}$ is a circular area. The timeaveraged active space and its various CPs are extremely difficult to determine in nature but are hypothesized to attract an equivalent number of insects under the same population conditions as would a corresponding $\mathrm{EAR}_{\mathrm{c}}$. Fortunately, the spherical EAR is easily determined by a time-averaged catch ratio of active and unbaited traps in the field as well as the interception area of the unbaited trap. Once this EAR is established, it is advantageous to transform it to an $\mathrm{EAR}_{\mathrm{c}}$ for use in encounter rate models of mass trapping and mating disruption (Byers 1993a, b, 1999; El-Sayed et al. 2006; Byers 2007, and unpublished). Of particular importance is that measurement of the EAR at different population densities should give the same value because it is derived from a ratio of active and passive catches (Byers et al. 1989).

No algorithms have been developed to transform the spherical EAR to a circular $E_{A} R_{c}$. In addition, the assumption that the $\mathrm{EAR}_{\mathrm{c}}$ can simulate encounter rates (catches) that are equivalent to that for plumes with more complex CP-active space has not been investigated. In contrast to molecular diffusion that is random, animals disperse in a correlated random walk (CRW) of forward direction because the direction of each step is correlated to some degree with their previous step direction (Turchin 1998; Byers 2001). My objective was to design graphical simulations of insects that move in a CRW while sometimes entering elongated active space plumes that have an inverse linear CP relationship with distance in order to calculate catch at various constant insect densities and flight speeds. This was to demonstrate merely that changes in $\mathrm{CP}$ and/or active space dimensions in this model would result in corresponding changes in catch. Then, for a particular catch obtained in the CP-active space model, I wanted to vary the $\mathrm{EAR}_{\mathrm{c}}$ circle of $\mathrm{CP}=1$ to iteratively solve for the same catch. This would demonstrate there is an $\mathrm{EAR}_{\mathrm{c}}$ that is equivalent to any complex interaction of active space and varying $\mathrm{CP}$, of which the $\mathrm{CP}$-active space is virtually impossible to obtain experimentally. In this case, the $\mathrm{EAR}_{\mathrm{c}}$ would provide a simple but effective alternative to a model that uses the active space and its spatially complex probabilities of attraction. The goal is then to determine the EAR in the field and convert it to an EAR for use in models of mating disruption and mass trapping in order to develop cost-effective control programs with these methods (Miller et al. 2006a, b; El-Sayed et al. 2006; Byers 2007).

\section{Methods and Materials}

Simulation of Insect Catch with Capture Probabilities in the Active Space of Plumes Insects were simulated in a twodimensional area with $x$-axis (xa) and $y$-axis (ya) that can be adjusted but was held at $1,000 \times 1,000 \mathrm{~m}$ in which a pheromone source was placed at $(\mathrm{xa} / 2, \mathrm{ya} / 2)$ and an active space plume extended as an angular sector of $15^{\circ}$ with a radial length of $100 \mathrm{~m}$ (Byers 1996b). Insects were simulated at a constant density in the area outside of the plume (usually $0.001 / \mathrm{m}^{2}$ or 997 insects for the plume above). Any insect that left the simulation area was replaced by another that was taking a half step from the perimeter at random into the area. Also, any insects that reached the source (i.e., caught) were counted and replaced outside the active space at random. Insects flew in the area according to a CRW and entered active space plumes as in earlier models (Byers 1996a, b, 1999, 2001). Each insect was given an initial direction and position outside the active space at random. Thereafter, each male followed a CRW made of a series of steps with a distance covered per second (speed), each step calculated as a polar vector from the former position. The vector length was the average distance traveled per second (usually $1 \mathrm{~m} / \mathrm{s}$ speed), and the direction was the former direction plus a turning angle chosen at random from a normal distribution, usually an $\mathrm{SD}^{\circ}$ (angular standard deviation) of $5^{\circ}$ centered on the former direction (Byers 2001).

Insects that entered the plume active space of length $L$ were assumed to reach the source with a probability that depended on their initial entry distance, $d$, from the source. Thus, to obtain $\mathrm{CP}$ as a function of distance from the source, a linear function beginning with $P=0.05$ at $L=$ $100 \mathrm{~m}$ and rising to a $\mathrm{CP}=1$ at the source was used:

$\mathrm{CP}=\frac{L-d+P \cdot d}{L}$

However, other values of $L, d \leq L$, and $0 \leq P \leq 1$ can be used. This equation generally accounts for the expectation, based on general knowledge of dosage-response relationships and mark-recapture studies (e.g., Zolubas and Byers 
1995), that catch is higher when entering the active space nearer the source than when entering farther downwind. However, the exact nature of the relationship is known poorly due to little information about variation in odor concentration, behavioral responses, and orientation time while approaching the source. In the model, an insect reaches the source (is caught) if a random number ( 0 to 1 ) is $\leq \mathrm{CP}$ at the point where the insect enters the active space (Eq. 1). If not caught, then the insect moves in the opposite direction away from the plume so only one test is made at that point in time. This algorithm merely approximates the effect of the plume CPs because only the edges of the plume are encountered.

The model was programmed in QuickBASIC 4.5 (Microsoft, Redmond, WA, USA) for use in simulations as well as Java 1.4.2_10 or later (Sun Microsystems, Santa Clara, CA, USA) for general demonstration on the Internet with a web browser and Java runtime installed (http://www. chemical-ecology.net/java2/act-ear.htm).

Simulation of Equivalent Insect Catch by the Effective Attraction Radius The same model parameters and algorithms as above were used except there was no plume but rather a circle representing the $\mathrm{EAR}_{\mathrm{c}}$ placed at $(\mathrm{xa} / 2, \mathrm{ya} / 2)$. Insects that entered the $\mathrm{EAR}_{\mathrm{c}}$ were captured with a probability of 1 . Since insects could be allowed steps that jump over the circular $\mathrm{EAR}_{\mathrm{c}}$, the algorithm for encountering the circle was that shown in Byers (1991, his Fig. 3). The goal was to find an $\mathrm{EAR}_{\mathrm{c}}$ in simulations with a catch that was approximately the same as for the assumed active space and CP relationship with the same CRW model parameters. This goal was facilitated by the functional response type I equation of Holling (1959). His equation defines the number of prey found $(y)$ by a predator as:

$y=a \cdot T_{\mathrm{s}} \cdot x$

where $T_{\mathrm{s}}$ is the total foraging time, $x$ is the prey density, and $a$ is the instantaneous attack rate. The attack rate is equal to the area covered by the predator each time unit and is, thus, the size of the predator or prey $\left(2 \times \mathrm{EAR}_{\mathrm{c}}\right)$ times the speed of prey or predator (depending on which is moving). This equation assumes one trap (i.e., predator) does not appreciably deplete insect densities and that predators/prey do not revisit previous areas.

In regard to an $\mathrm{EAR}_{\mathrm{c}}$ of a pheromone plume (or trap), substitution of the relevant variables into Eq. 2 and solution for the radius $\left(\mathrm{EAR}_{\mathrm{c}}\right)$ gives the equation:

$\mathrm{EAR}_{\mathrm{c}}=\frac{C \cdot \mathrm{xa} \cdot \mathrm{ya}}{T \cdot S \cdot 2 \cdot N}$

where $T$ is the test duration (same as $T_{\mathrm{s}}$ above), $S$ is the insect speed, $C$ is the number caught, and $N$ is the number of insects in the area (xa·ya) or prey density $(x)$. In the simulations, $N$ is known but would not be measured easily in nature. Thus, the catch obtained in the CP-active space model (mean of ten simulations) was used in Eq. 3 to predict an equivalent $\mathrm{EAR}_{\mathrm{c}}$. Simulations were then performed to bracket the predicted $\mathrm{EAR}_{\mathrm{c}}$ by incrementing in 3-m steps the simulated $\mathrm{EAR}_{\mathrm{c}}$ from 1 to twice the predicted (each increment had ten simulations). Linear regression was used to solve for the $\mathrm{EAR}_{\mathrm{c}}$ that caught the equivalent catch as that in the $\mathrm{CP}$-active space response area.

To gain insight about effects of various model parameters used in both the CP-active space and $\mathrm{EAR}_{\mathrm{c}}$ in models, simulation results were compared to predicted results of Eq. 3. Both $\operatorname{EAR}_{\mathrm{c}}(1,2,5,10$, and $20 \mathrm{~m})$ and number of insects $(100,200,500,1,000$, and 2,000) were varied in simulations of ten replicates each for all combinations of these parameters. The standard deviation of turning angle distribution $\left(\mathrm{SD}^{\circ}\right)$ was varied similarly $(0,2,5,10,15,20$, 25 , and $30^{\circ}$ ) in simulations to test for effects on catch.

Relationship Between EAR of Sphere and EAR $R_{c}$ of Circle Used in Models The original EAR (Byers et al. 1989) was the radius of a sphere as calculated by the equation:

$\mathrm{EAR}=\sqrt{\frac{A_{\mathrm{c}} \cdot 2 \cdot r \cdot h}{P_{\mathrm{c}} \cdot \pi}}$

where $A_{\mathrm{c}}$ is the catch on the active trap (semiochemical), $P_{\mathrm{c}}$ is the catch on the passive (unbaited) trap, and $r$ is the radius and $h$ is the height of the passive trap cylinder. For hanging flat panel traps of width $\times$ height, $2 \cdot r \cdot h$ in Eq. 4 can be substituted with $(0.637 \cdot$ width height $)$ for the average interceptive trap area, TA (Byers et al. 1989). In simulation models, the EAR is better described in a new way:

$\mathrm{EAR}_{\mathrm{c}}=\frac{A_{\mathrm{c}} \cdot T A / 2}{P_{\mathrm{c}} \cdot F_{L}}$

where $F_{\mathrm{L}}$ is the thickness of the air layer in which insects search primarily while flying. Regressions were done by enlarging $r$ from 0.1 to $2 \mathrm{~m}$ with various $h, A_{\mathrm{c}}$, and $P_{\mathrm{c}}$ in $F_{\mathrm{L}}$ from 1 to $10 \mathrm{~m}$ thickness in order to determine the relationships between Eqs. 4 and 5. The goal was to try and convert EAR of Eq. 4, measured conveniently with two trap catches, to corresponding $\mathrm{EAR}_{\mathrm{c}}$ of Eq. 5, which is most useful in simulation models.

The scientific literature was searched (BIOSIS Previews) for articles on flight heights of insects caught by traps to estimate the effective flight layer of search, $F_{\mathrm{L}}$, as well as catches on attractant and passive sticky traps to estimate EAR from Eq. 4 or $\mathrm{EAR}_{\mathrm{c}}$ from Eq. 5. The $F_{\mathrm{L}}$ was estimated from published catches at various heights by calculating the mean height of catch and standard deviation (SD) by using standard statistical formulas (McCall 1970). In some 
reports, actual catch was not given but rather the total catch proportion at each trapping height. It was assumed that at least 100 insects were caught among all trap heights. Effects of this assumption were tested on simulated data of either 20,100, or 2,000 catches at five trap levels $(1,2,3$, 4 , and 5) assuming catch proportions of $0.1,0.3,0.3,0.2$, 0.1 , respectively. The $F_{\mathrm{L}}$ was then calculated from $\mathrm{SD} \cdot \sqrt{2 \cdot \pi}$. This gives a probability area equal to the height of the normal distribution $(1 /(\mathrm{SD} \cdot \sqrt{2 \cdot \pi})$; McCall 1970) times the layer's thickness that would equal the area under the normal curve (Byers, unpublished).

\section{Results}

Simulation of Insect Catch with Capture Probabilities in the Active Space of Plumes The simulation of the $15^{\circ}$-sector $\times$ $100-\mathrm{m}$ long CP-active space response plume in the square kilometer arena caught an average of $121.4 \pm 6.9( \pm 95 \%$ confidence limits (C.L.) $N=10$ ) insects when a constant density of 1,000 in the area each took 3,600 steps of $1 \mathrm{~m}$ each and turned with an $\mathrm{SD}^{\circ}$ of $5^{\circ}$. By assuming the same simulation conditions and using Eq. 3, an equivalent number of insects should be caught by a predicted $\mathrm{EAR}_{\mathrm{c}}$ of $16.86 \mathrm{~m}$. An increase of the plume length $(X)$ from 50 to $200 \mathrm{~m}$ increased the catch $(Y)$ as expected as a linear function $(Y=$ $\left.5.5+1.145 X, R^{2}=1.0, N=7\right)$. Other CP-response surfaces in the active space altered the simulated catch depending on the values. For example, assuming an exponential decline in probability with distance from the source (Mason et al. 1990; Zolubas and Byers 1995), $\mathrm{CP}=P / \exp (d)^{5 / L}$ with $P=1$, gave a mean catch of $43.6 \pm 6.08$ with the parameters above. This predicts an $\mathrm{EAR}_{\mathrm{c}}$ of $6.06 \mathrm{~m}$ by using Eq. 3. Simulations also showed that the $\mathrm{CRW}$ parameter of the $\mathrm{SD}^{\circ}$ of angular turns affected catch, as is presented below.

Simulation of Equivalent Insect Catch by the Effective Attraction Radius An increase in the number of insects in the arena (density) caused a linear increase in catch (Table 1) in accordance with that predicted from solving catch $(C)$ in Eq. 3. Also, an increase in the $\mathrm{EAR}_{\mathrm{c}}$ caused a linear increase in catch (Table 1) that was close to that predicted. Other simulations in which the $\mathrm{SD}^{\circ}$ of turning angles was increased from straight at $0^{\circ}$ to sinusoidal at $30^{\circ}$ gave results that were surprising (Table 2). At an $\mathrm{SD}^{\circ}$ of $0^{\circ}$, the catch was $60.3 \pm 5.9$, which was less than 72 predicted from Eq. 3, while as the $\mathrm{SD}^{\circ}$ was increased to $5^{\circ}$, the catch increased to $71.3 \pm 6.4$ and was indistinguishable from predicted. Further increases in $\mathrm{SD}^{\circ}$ to $10^{\circ}(65.7 \pm 4.1), 15^{\circ}$ $(56 \pm 4.8), 20^{\circ}(42.2 \pm 4.2), 25^{\circ}(33.5 \pm 2.6)$, and $30^{\circ}(27.9 \pm$ 4.4) caused the catch to decline well below predicted. The general reasons for this will be discussed below.

The $\mathrm{EAR}_{\mathrm{c}}$ was increased incrementally in simulations from $1 \mathrm{~m}$ to about twice the predicted $\mathrm{EAR}_{\mathrm{c}}$ in order to find the catch that was equivalent to the catch by the $\mathrm{CP}$-active space model. The results fit a linear function, $Y=7.209 \mathrm{X}+$ $0.26\left(R^{2}=1.0, N=11\right.$, Fig. 2). By using a catch of 121.4 for $Y$ above in the CP-active space plume, an equivalent $\mathrm{EAR}_{\mathrm{c}}$ is found by solving for $X=(Y-0.26) / 7.209=16.80 \mathrm{~m}$, which is close to $16.86 \mathrm{~m}$ predicted from Eq. 3. Another random seed gave an equivalent $\mathrm{EAR}_{\mathrm{c}}$ of $16.85 \mathrm{~m}$. This shows in principle that any $\mathrm{CP}$-active space response surface can be transformed into an equivalent $\mathrm{EAR}_{\mathrm{c}}$. While the $\mathrm{CP}$-active space response surface is exceedingly difficult to measure, the EAR can be found experimentally in the field (see below).

Relationship between EAR of Sphere and EAR $R_{c}$ of Circle Used in Models There is a positive linear relationship between radius of the passive trap and the EAR of the sphere, while the $\mathrm{EAR}_{\mathrm{c}}$ increases as a function of the square of the trap radius (Fig. 3). The exact relationships depend on the ratio of catch (active/passive), the interception area of the passive trap, and in the case of the $\mathrm{EAR}_{\mathrm{c}}$, the effective flight layer thickness. When the $\operatorname{EAR}_{c}(Y)$ is plotted against $\operatorname{EAR}(X)$, the $\operatorname{EAR}_{\mathrm{c}}$ increases as the square of the EAR ( $Y=a X^{2}$, Fig. 4). This relationship does not depend on the catch ratio or the dimensions of the passive trap; however, the proportion of the passive trap height that intercepts the flight layer $\left(F_{\mathrm{L}}\right)$ does influence the power curves. For example, if the $F_{\mathrm{L}}=10 \mathrm{~m}$ then $Y=0.157 X^{2}$,

Table 1 Effect of EAR $\mathrm{E}_{\mathrm{c}}$ and number of insects on catch when each insect moved 3,600 steps of $1 \mathrm{~m}(1 \mathrm{~m} / \mathrm{s})$ with an $\mathrm{SD}^{\circ}$ of turning angles of $5^{\circ}$ in an area of $1,000 \times 1,000 \mathrm{~m}$ (catches are means \pm 95 C.L. of ten simulations)

\begin{tabular}{llcccc}
\hline \multicolumn{7}{c}{ Effective attraction radius $\left(\mathrm{EAR}_{\mathrm{c}} ; \mathrm{m}\right)$} & & & \\
\cline { 2 - 6 } Number of insects per square kilometer & 1 & 2 & 5 & 10 & 20 \\
\hline 100 & $0.6 \pm 0.5(0.72)^{\mathrm{a}}$ & $1.5 \pm 0.8(1.44)$ & $3.5 \pm 1.3(3.6)$ & $7.9 \pm 2.1(7.2)$ & $16.4 \pm 2.4(14.4)$ \\
200 & $1.4 \pm 1.1(1.44)$ & $3.3 \pm 1.5(2.88)$ & $9.1 \pm 2.5(7.2)$ & $14.1 \pm 2.4(14.4)$ & $28.4 \pm 3.1(28.8)$ \\
500 & $4.7 \pm 1.0(3.6)$ & $8.0 \pm 2.5(7.2)$ & $17.3 \pm 2.8(18)$ & $37.3 \pm 3.4(36)$ & $70.7 \pm 4.8(72)$ \\
1,000 & $8.5 \pm 1.6(7.2)$ & $12.5 \pm 1.6(14.4)$ & $33.9 \pm 4.9(36)$ & $67.9 \pm 6.6(72)$ & $139.2 \pm 8.8(144)$ \\
2,000 & $14.4 \pm 3.1(14.4)$ & $28.8 \pm 3.0(28.8)$ & $68 \pm 7.9(72)$ & $139.4 \pm 5.1(144)$ & $290.6 \pm 13.2(288)$ \\
\hline
\end{tabular}

${ }^{a}$ Values in parentheses are predicted catch $(C)$ by solving Eq. 3. 
Table 2 Effect of $\mathrm{SD}^{\circ}$ of turning angles on catch by an $\mathrm{EAR}_{\mathrm{c}}$ of $10 \mathrm{~m}$ when each insect moved 3,600 steps in an area of $1,000 \times 1,000 \mathrm{~m}$ with a constant 1,000 insects (catches are means \pm 95 C.L. of ten simulations)

\begin{tabular}{|c|c|c|c|c|}
\hline \multirow[b]{2}{*}{$\mathrm{SD}^{\circ}$ of turn angles } & \multicolumn{4}{|c|}{ Average speed of insect $(\mathrm{m} / \mathrm{s})$} \\
\hline & 0.1 & 0.5 & 1 & 2 \\
\hline 0 & $6.0 \pm 0.6(7.2)^{\mathrm{a}}$ & $27.9 \pm 3.5(36)$ & $60.3 \pm 5.9(72)$ & $115.4 \pm 7.2(144)$ \\
\hline 2 & $5.8 \pm 1.5(7.2)$ & $33 \pm 4.7(36)$ & $66.5 \pm 6.5(72)$ & $123.2 \pm 8.3(144)$ \\
\hline 5 & $6.3 \pm 1.1(7.2)$ & $35.5 \pm 3.8(36)$ & $71.3 \pm 6.4(72)$ & $140.6 \pm 10.3(144)$ \\
\hline 10 & $3.8 \pm 1.2(7.2)$ & $31.1 \pm 3.7(36)$ & $65.7 \pm 4.1(72)$ & $136.6 \pm 6.8(144)$ \\
\hline 15 & $3.0 \pm 1.1(7.2)$ & $20.8 \pm 3.4(36)$ & $56 \pm 4.8(72)$ & $131 \pm 7.0(144)$ \\
\hline 20 & $1.4 \pm 0.8(7.2)$ & $16.9 \pm 2.7(36)$ & $42.2 \pm 4.2(72)$ & $113.6 \pm 6.0(144)$ \\
\hline 25 & $1.7 \pm 0.9(7.2)$ & $12.0 \pm 3.5(36)$ & $33.5 \pm 2.6(72)$ & $96 \pm 8.0(144)$ \\
\hline 30 & $1.1 \pm 0.6(7.2)$ & $9.1 \pm 1.4(36)$ & $27.9 \pm 4.4(72)$ & $80 \pm 5.6(144)$ \\
\hline
\end{tabular}

${ }^{\text {a }}$ Values in parentheses are predicted catch (C) by solving Eq. 3.

while if $F_{\mathrm{L}}=3 \mathrm{~m}$, then $Y=0.524 X^{2}$. Plotting of the regression coefficient $a$ above against $F_{\mathrm{L}}$ gives an inverse power relationship $a=1.571 / F_{\mathrm{L}}$. This $a$ used in $Y=a X^{2}$ above can be used with an effective flight layer thickness to convert any spherical EAR to the corresponding model $\mathrm{EAR}_{\mathrm{c}}$ with the equation:

$\mathrm{EAR}_{\mathrm{c}}=\frac{1.571 \cdot \mathrm{EAR}^{2}}{F_{L}}$

It turns out that 1.571 is $\pi / 2$.

Over 100 articles were found on insect flight heights of which some were suitable to estimate the flight layer of search, $F_{\mathrm{L}}$ (Table 3). Most insects, while searching for mates and/or food, fly within a few meters above the ground (Table 3). Insects that are of agricultural importance fly within an even thinner layer just above the canopy. In some studies, only proportions of catch at each trap height were reported, so $N=100$ or 1,000 insects were assumed when calculating mean height of catch and SD. However,

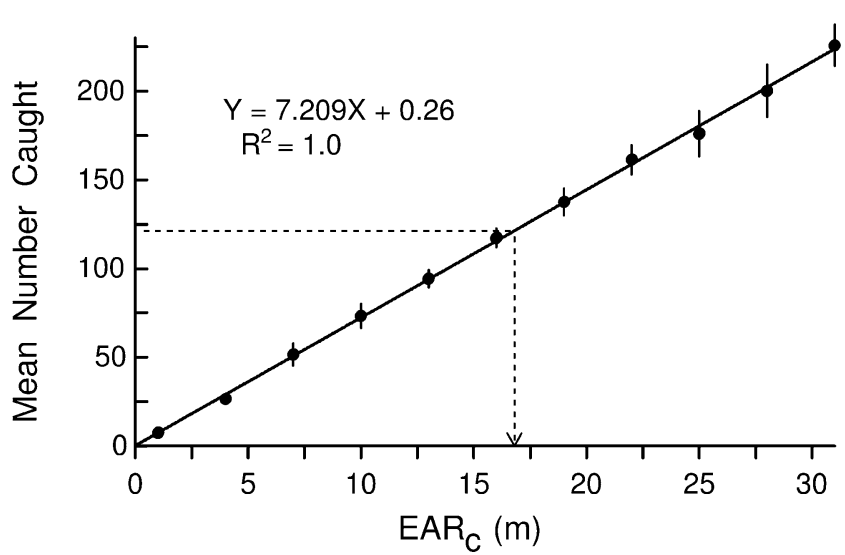

Fig. 2 Mean number of insects caught in an area of 1,000 $\times 1,000 \mathrm{~m}$ with a constant density of 1,000 insects, each taking 3,600 steps of $1 \mathrm{~m}$ with a $5^{\circ} \mathrm{SD}$ of turning angle distribution as a function of $\mathrm{EAR}_{\mathrm{c}}$ in meters (bars represent 95\% C.L., ten simulations each point) there was little possible error from this assumption since calculation with 20,100 , or 2,000 catch on specific proportions (see "Methods and Materials") gave the same mean height of catch $(2.9 \mathrm{~m})$, while the $\mathrm{SD}$ also was similar at $1.165,1.142$, or 1.136 , respectively.

A few studies were found on catches of attractant and passive sticky traps of various insects and used to calculate EAR from Eq. 4, which was then used with an estimated $F_{\mathrm{L}}$ to determine an $\mathrm{EAR}_{\mathrm{c}}$ by Eq. 6 (Table 4). The $\mathrm{EAR}_{\mathrm{c}}$ is directly proportional to the ratio of catch, so the radius of its circle catches in direct proportion to its size in simulations as expected.

\section{Discussion}

The active space concept is readily understood as the plume area where male moths detect female moth pheromone (Sower et al. 1971; Nakamura and Kawasaki 1977; Baker and Roelofs 1981; Elkinton and Cardé 1984). It is time-

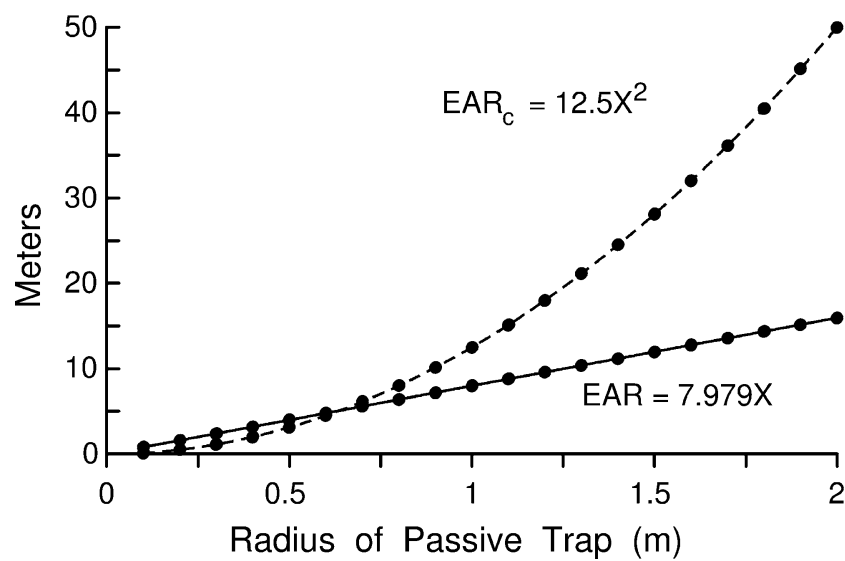

Fig. 3 EAR from Eq. 4 and $\mathrm{EAR}_{\text {c }}$ from Eq. 5 as a function of the passive cylinder trap radius when the pheromone trap caught 50 times more than the passive trap (height of passive trap was twice the radius and $F_{\mathrm{L}}=8 \mathrm{~m}$ ) 


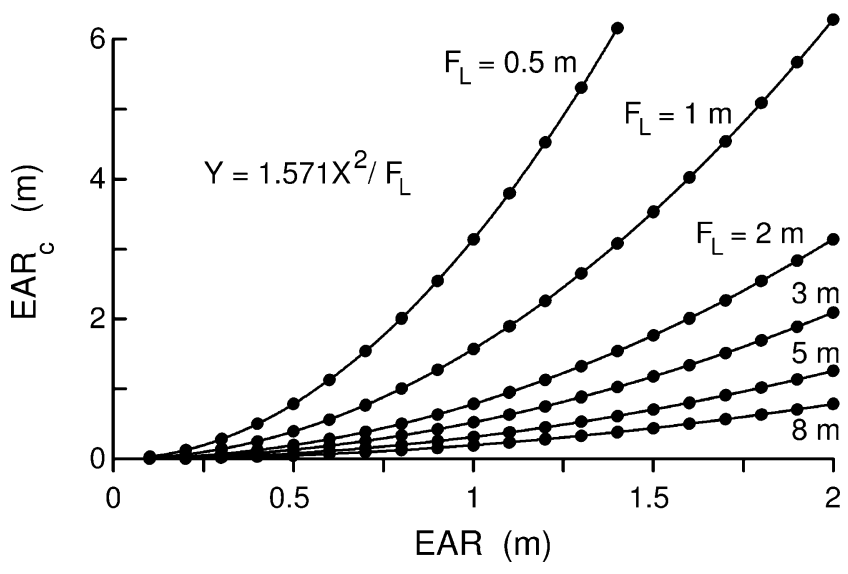

Fig. $4 \mathrm{EAR}_{\mathrm{c}}$ as a function of EAR in various flight layers

consuming and tedious to measure the general dimensions of the active space for a particular pheromone release rate and moth species by observing male wing-fanning in cages at many distances downwind from the source (Elkinton and Cardé 1984; Elkinton et al. 1984). Knowledge of the active space would be useful in mass-trapping programs if moths entering the space have a constant probability of being caught by a trap. Unfortunately, a constant probability is unlikely and not consistent with our knowledge of moth orientation behavior in wind tunnels or in the field. It is likely that males entering the active space far from the pheromone source have lower CP than males entering the active space nearer the source (McClendon et al. 1976; Branco et al. 2006). However, the difficulties of determining the many CPs in the active space are enormous, and as such, no studies have attempted precise measurements. Still, knowledge of the CP-active space dimensions could be useful in modeling of mate- and host-finding as well as mating disruption and mass trapping with synthetic pheromone dispensers (Byers 2007).

The simulations demonstrated that males encountering CP-active space plumes of a specific dimension reach the pheromone source at a rate that depends on the model parameters chosen. The equivalent attraction rate of a CPactive space plume of any arbitrary complexity was obtained by adjusting the circular $\mathrm{EAR}_{\mathrm{c}}$ in size until this caught an equivalent number during the same period. In modeling insect encounters with semiochemical lures, the use of highly complex CP-active space plumes is less desirable than the simple-to-measure-and-use $\mathrm{EAR}_{\mathrm{c}}$.

The EAR, as used originally (Byers et al. 1989) in Eq. 4, is calculated from the passive trap interception area as seen from any particular direction multiplied by the ratio of catch on the pheromone trap $\left(A_{\mathrm{c}}\right)$ and passive trap $\left(P_{\mathrm{c}}\right)$. This interception area is solved for a circular area of radius EAR (also the radius of a sphere of this size). The EAR (or $E A R_{c}$ ) is useful to compare the relative strengths of semiochemical attractants of various blends and release rates among insect species and studies. Catches alone are not sufficient for such comparisons because catch depends on trap dimensions as well as on population density, both of which vary between locations and times. In contrast to simple catch comparisons, the EAR is not affected significantly by flight density variations, as Eq. 4 uses a ratio of attractive to passive catches that, in principle, would not vary with flight density. It is relatively simple to obtain an average catch on passive sticky traps as well as one on attractive pheromone traps. The size of the passive trap then determines the EAR as long as there is some catch on both trap types (division by zero is undefined).

An insect species with a larger EAR than a second species generally means that individuals of the first species are attracted from a longer distance, assuming the $\mathrm{CP}$ gradients in the two active spaces are about the same. However, if the CP-active spaces are different, it is possible that the second species could, on average, be attracted from further away. Because we have little or no knowledge of the $\mathrm{CP}$-active space, it is assumed that the larger the EAR, the longer the average distance of attraction. In the simulations, insects did not reach the inner areas of the plume, so the response surface actually applied only on the periphery, while in nature, $\mathrm{CP}$ could be observed anywhere in the plume. If simulated insects were allowed to continue into the plume, they would have a new chance of being caught according to the $\mathrm{CP}$ at each step, which would incorrectly cause nearly all to be caught. The EAR with $\mathrm{CP}=1$ does not exist in nature, as does a plume, but merely acts as a convenient method of comparison of attractive bait strengths or as a convenient substitute for plumes (as $\mathrm{EAR}_{\mathrm{c}}$ ) in encounter rate models. The attractive trap must catch more than the passive trap, the passive trap should catch some insects, and higher catches on many passive traps will improve the accuracy of the EAR measurement. The attractive trap should be placed far enough from the passive trap as to hardly influence the latter's catch, but both kinds of traps should be within the same area of flight density. The EAR is usually up to only a few meters and, thus, considerably smaller than the attraction range (maximum orientation distance), the sampling range (maximum distance over which an insect can reach a trap in a given time; Wall and Perry 1987), or the average distance of attraction. A related concept is the effective sampling area (trap catch divided by the population density; Turchin and Odendaal 1996), which, for European pine sawflies Neodiprion sertifer Geoffroy, released away from a pheromone trap, was estimated to have a radius of $125 \mathrm{~m}$ (Östrand and Anderbrant 2003), much larger than any expected EAR.

The EAR calculation is convenient to measure in the field with sticky traps that sample a small portion of the flight layer (usually within meters of the ground for most agricultural insects). The trouble in modeling with the EAR as measured 
Table 3 Mean height of catch $\pm \mathrm{SD}(\mathrm{m})$ and the effective $F_{\mathrm{L}}$ of various insects calculated from catches at trap heights reported in the literature

\begin{tabular}{|c|c|c|c|c|c|c|}
\hline Species & Trapping method & Range of trap heights & $\begin{array}{l}\text { Number of } \\
\text { trap heights }\end{array}$ & Total catch ${ }^{\mathrm{a}}$ & $\begin{array}{l}\text { Mean height } \\
\text { of catch } \pm \mathrm{SD}\end{array}$ & $F_{\mathrm{L}}(\mathrm{m})$ \\
\hline
\end{tabular}

Coleoptera: Scolytidae

Hylurgops palliatus (Gryllenhal) ${ }^{\mathrm{b}}$

Ips typographus $(\mathrm{L} .)^{\mathrm{b}}$

T. piniperda $(\mathrm{L} .)^{\mathrm{b}}$

Trypodendron domensticum (L.) $)^{\mathrm{b}}$

Cryphalus abietus (Ratz.) ${ }^{\mathrm{b}}$

Pityogenes bidentatus (Herbst) ${ }^{\mathrm{b}}$

Pityogenes chalcographus (L.) ${ }^{\mathrm{b}}$

Pityogenes quadridens (Hartig) ${ }^{\mathrm{b}}$

Ips calligraphus (Germar) ${ }^{\mathrm{c}}$

Ips grandicollis (Eichh.) ${ }^{\mathrm{c}}$

Hylastes tenius Eichh. ${ }^{\mathrm{c}}$

Xyleborus affinis (Eichh.) ${ }^{\mathrm{c}}$

Xyleborinus saxesini (Ratz.) ${ }^{\mathrm{c}}$

Ambrosiodmus lecontei Hopk. ${ }^{\mathrm{c}}$

Xylosandrus compactus (Eichh.) ${ }^{\mathrm{c}}$

Coleoptera: Curculionidae

Balanogastris kolae (Desbr.) ${ }^{\mathrm{d}}$

Anthonomus grandis Boheman ${ }^{\mathrm{e}}$

Hylobius pales (Herbst.) $)^{\mathrm{c}}$

Coleoptera: Platypodidae

Platypus compositus Say ${ }^{\mathrm{c}}$

Coleoptera: Scarabaeidae

Phyllophaga crinita Burmeister ${ }^{\mathrm{f}}$

Hoplia equina LeConte ${ }^{\mathrm{g}}$

Coleoptera: Chrysomelidae

Diabrotica virgifera LeConte ${ }^{\mathrm{h}}$

Trirhabda virgata LeConte ${ }^{\mathrm{i}}$

Phyllotreta cruciferae (Goeze) $)^{j}$

Coleoptera: Elateridae

Ctenicera appropinquans

(Randall) $^{\mathrm{k}}$

Ctenicera pulchra (LeConte) ${ }^{\mathrm{k}}$

Ctenicera tarsalis (Melsheimer) ${ }^{\mathrm{k}}$

Melanotus similes (Kirby) ${ }^{\mathrm{k}}$

Sericus brunneus $(\mathrm{L} .)^{\mathrm{k}}$

Lepidoptera: Geometridae

Idaea squamipunctata Warren ${ }^{1}$

Hypomecis costaria Guenée ${ }^{1}$

Ornithospila avicularia Guenée ${ }^{1}$

Godonela avitusaria Walker ${ }^{1}$

Hypomecis tetragonata Walker $^{1}$

St-screen

Lepidoptera: Nymphalidae

Heliconius numata Cramer males ${ }^{\mathrm{m}}$

Heliconius numata Cramer

females $^{\mathrm{m}}$

Hemiptera: Cicadellidae

Circulifer tenellus (Baker) males ${ }^{\mathrm{n}}$

Circulifer tenellus (Baker) females ${ }^{\mathrm{n}}$

Scaphytopius magdalensis

(Provancher) $^{\mathrm{o}}$

Hemiptera: Aleyrodidae

Parabemisia myricae (Kuwana) ${ }^{\mathrm{p}}$

Bemisia tabaci Gennadius males ${ }^{\mathrm{q}}$

Bemisia tabaci Gennadius females ${ }^{\mathrm{q}}$

W-St-card
St-screen

St-screen

St-screen

St-screen

St-screen

St-screen

St-screen

X-pane

X-pane

$\mathrm{X}$-pane

X-pane

X-pane

X-pane

$\mathrm{X}$-pane

B-St-card

Y-St-X-pane-P

X-pane

X-pane

St-card-UV

$\mathrm{X}$-pane-P

Y- St-box

W- St-card

Y- St-card

Y-X-pane

Y-X-pane

Y-X-pane

$\mathrm{Y}-\mathrm{X}$-pane

$\mathrm{Y}-\mathrm{X}$-pane

R-light

R-light

R-light

R-light

R-light

$0.7-11.5$

$0.7-11.5$

$0.7-11.5$

$0.7-11.5$

$0.7-11.5$

$0.7-11.5$

$0.7-11.5$

1-5

$1-5$

$1-5$

$1-5$

$1-5$

$1-5$

$1-5$

0.4-2.2

$0-9.1$

$1-5$

1-5

$0.15-2.28$

$0.2-1$

3.05-7.62

1-4

0.5-7

$0.8-14.3$

0.8-14.3

0.8-14.3

0.8-14.3

$0.8-14.3$

1-30

1-30

1-30

1-30

1-30

B-fly-net

B-fly-net

Y-St-card

$0.11-2.81$

Y-St-card

Y-St-card

Y-St-card

W-St-card
$0.11-2.81$

$0.12-1.82$

0.76-6.1

$0.16-7.36$

$0.16-7.36$

10
10
10
10
10
10
10
10
3
3
3
3
3
3
3

10

10

10

10

10

10

10

10

3

3

3

3

3

3

3

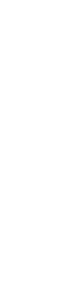

86
103

103
10

17

242

23

84

50

(100)

(100)

(100)

(100)

(100)

(100)

(100)

701

22,310

(100)

(100)

3,244

852

0.59

$4.98 \pm 2.63$

6.59

$4.63 \pm 2.75$

$5.98 \pm 3.00$

6.89

$2.82 \pm 1.67$

7.52

$3.44 \pm 2.73$

$3.10 \pm 1.62$

$6.89 \pm 2.90$

$4.08 \pm 2.80$

$2.62 \pm 1.31$

$3.43 \pm 1.29$

$2.43 \pm 0.91$

$1.33 \pm 0.94$

$2.25 \pm 1.44$

$2.38 \pm 1.69$

$1.78 \pm 1.31$

$0.68 \pm 0.44$

$1.65 \pm 1.96$

$2.24 \pm 1.66$

4.91

$1.67 \pm 1.07$

2.69

4,528

377

173

$4.12 \pm 1.44$

$1.75 \pm 1.00$

$2.68 \pm 1.82$

2.51

115

$5.40 \pm 3.83$

9.59

$5.14 \pm 3.89$

$3.88 \pm 3.07$

$2.50 \pm 1.77$

9.74

74

97

118

$6.56 \pm 3.72$

7.70

4.43

9.31

529

$18.02 \pm 11.13$

27.90

$2.17 \pm 3.88$

$8.98 \pm 8.93$

9.72

$9.38 \pm 10.86$

63

37

$10.54 \pm 8.94$

22.42

90

$2.30 \pm 0.95$

2.38

34

$1.09 \pm 0.64$

1.61

2,905

657

(100)

$0.17 \pm 0.27$

0.67

$0.23 \pm 0.35$

0.89

$0.30 \pm 0.19$

0.48

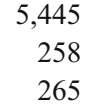

$1.93 \pm 1.42$

3.55

$1.09 \pm 1.82$

4.55

265

$1.23 \pm 1.89$

4.73 
Table 3 (continued)

\begin{tabular}{|c|c|c|c|c|c|c|}
\hline Species & Trapping method & Range of trap heights & $\begin{array}{l}\text { Number of } \\
\text { trap heights }\end{array}$ & Total catch ${ }^{\mathrm{a}}$ & $\begin{array}{l}\text { Mean height } \\
\text { of catch } \pm \mathrm{SD}\end{array}$ & $F_{\mathrm{L}}(\mathrm{m})$ \\
\hline \multicolumn{7}{|l|}{ Hemiptera: Miridae } \\
\hline $\begin{array}{l}\text { Lygus lineolaris } \\
\text { (P. de Beauvois) males }{ }^{\mathrm{r}}\end{array}$ & W-St-card & $0.6-3.05$ & 3 & 1,780 & $0.93 \pm 0.66$ & 1.66 \\
\hline $\begin{array}{l}\text { Lygus lineolaris } \\
\text { (P. de Beauvois) females }{ }^{\mathrm{r}}\end{array}$ & W-St-card & $0.6-3.05$ & 3 & 1,396 & $0.99 \pm 0.71$ & 1.79 \\
\hline \multicolumn{7}{|l|}{ Thysanoptera: Thripidae } \\
\hline $\begin{array}{l}\text { Frankliniella occidentalis } \\
{\text { (Pergande })^{\mathrm{s}}}^{\text {Per }}\end{array}$ & Y-St-card & $0.25-2.5$ & 5 & $(1,000)$ & $1.14 \pm 0.70$ & 1.76 \\
\hline \multicolumn{7}{|l|}{ Diptera: Agromyzidae } \\
\hline Liriomyza trifolii (Burgess) fall ${ }^{t}$ & Y-St-card & $0.3-1.5$ & 5 & $(100)$ & $0.55 \pm 0.39$ & 0.99 \\
\hline Liriomyza trifolii (Burgess) spring ${ }^{\mathrm{t}}$ & Y-St-card & $0.3-1.5$ & 5 & $(100)$ & $0.50 \pm 0.27$ & 0.69 \\
\hline
\end{tabular}

St-screen Sticky screen; X-pane cross window panes; $B$-St-card brown sticky card; $Y$-St-X-pane-P yellow sticky cross panes with pheromone bait; St-card-UV sticky card with UV light; $X$-pane-P cross window panes with pheromone bait; $Y$-St-box yellow sticky box; $W$-St-card white sticky card; Y-St-card yellow sticky yellow card; Y-X-pane yellow cross panes; R-light Rothamsted light trap; B-fly-net butterfly net pole

${ }^{a}$ Trap catch reported as proportions so catch in parentheses was assumed in order to calculate mean height of catch and variation.

${ }^{\mathrm{b}}$ Byers et al. 1989

${ }^{c}$ Atkinson et al. 1988

${ }^{\mathrm{d}}$ Ivbijaro and Daramola 1977

e Rummel et al. 1977

${ }^{\mathrm{f}}$ Stone 1986

${ }^{\mathrm{g}}$ Weber et al. 2005

${ }^{\mathrm{h}}$ VanWoerkom et al. 1983

${ }^{\mathrm{i}}$ Messina 1982

${ }^{j}$ Lamb 1983

${ }^{\mathrm{k}}$ Boiteau et al. 2000

${ }^{1}$ Intachat and Holloway 2000

m Joron 2005

${ }^{\mathrm{n}}$ Meyerdirk and Oldfield 1985

${ }^{\circ}$ Meyer and Colvin 1985

${ }^{\mathrm{p}}$ Meyerdirk and Moreno 1984

${ }^{\mathrm{q}}$ Isaacs and Byrne 1998

${ }^{\mathrm{r}}$ Stewart and Gaylor 1991

s Pearsall and Myers 2001

${ }^{\mathrm{t}}$ Chandler 1985.

in the field is that its radius is a sphere and extends vertically and horizontally in three dimensions and often would not fill the flight layer or could theoretically protrude above the flight layer. Byers (2007) used a circular EAR in simulation models of mating disruption and mass trapping and implied that field-measured EAR could be used to predict catch rates. However, in the present work, I found that the spherical EAR must be transformed into the circular $E_{A R}$ for appropriate prediction due to the effect of the effective flight layer, $F_{\mathrm{L}}$, which varies among species. It is simpler to model insect search in two dimensions because they fly over wide areas in essentially a two-dimensional layer of a few meters thickness. However, if the passive trap is a tall cylinder that extends vertically through the flight layer, then the $\mathrm{EAR}_{\mathrm{c}}$ of Eq. 5 can be measured in nature. In this case, the interception is proportional to the radius of the cylinder in simulations with $\mathrm{CP}=1$ (Fig. 1c) or as a circle of $\mathrm{EAR}_{\mathrm{c}}$.

Byers et al. (1989) measured $\mathrm{EAR}_{\mathrm{c}}$ in the field with several 12-m columns of sticky cylinder traps baited or not with attractants for insects. In this study, the flight layer was sampled throughout by the sticky traps whose catch was multiplied by 4 to account for gaps in coverage. Therefore, the $\mathrm{EAR}_{\mathrm{c}}$ of the aggregation pheromone baits of the bark beetle Ips typographus (L.) is simply the ratio of catches times the passive trap radius $(0.7 \mathrm{~m}$, Table 4$)$. These ten baits were released at one point in another study (Schlyter et al. 1987) that gave an EAR of $1.9 \mathrm{~m}$, which, assuming an $F_{\mathrm{L}}$ of $8 \mathrm{~m}$, gives an identical $\mathrm{EAR}_{\mathrm{c}}$ of $0.7 \mathrm{~m}$ (Eq. 6). Other $F_{\mathrm{L}}$ estimates would alter the calculated $\mathrm{EAR}_{\mathrm{c}}$. For example, the estimate of $F_{\mathrm{L}}$ for I. typographus from flight height data (Table 3) was $6.9 \mathrm{~m}$, giving an $\mathrm{EAR}_{\mathrm{c}}$ of $0.82 \mathrm{~m}$. Equation 6 can be used to convert the EAR to $\mathrm{EAR}_{\mathrm{c}}$ if a flight layer is estimated from observations or trap catches at various heights. By using data from Byers et al. (1989) for two species of bark beetle caught on baits of host tree monoterpenes or aggregation pheromone components, the two types of EAR calculations are compared (Table 4). In these cases, the $\mathrm{EAR}_{\mathrm{c}}$ was smaller than the spherical EAR because of the size of the 
Table 4 EAR and EAR of monoterpene or aggregation pheromone component release rates attractive to bark beetles, Tomicus piniperda and Ips typographus, respectively, based on passive and active catches on cylindrical sticky trap screens and effective flight layer estimate (from Table 3)

\begin{tabular}{|c|c|c|c|c|c|c|}
\hline \multirow[t]{2}{*}{ Test } & \multicolumn{2}{|c|}{ Insect catch } & \multirow{2}{*}{$\begin{array}{l}\text { Passive trap interception } \\
\text { area }\left(\mathrm{m}^{2}\right)\end{array}$} & \multirow[t]{2}{*}{ EAR sphere $(\mathrm{m})$} & \multirow{2}{*}{$\begin{array}{l}\text { Flight Layer } \\
\text { estimate }(\mathrm{m})\end{array}$} & \multirow[t]{2}{*}{$\mathrm{EAR}_{\mathrm{c}}(\mathrm{m}$} \\
\hline & Passive & Active & & & & \\
\hline \multicolumn{7}{|l|}{ Tomicus piniperda } \\
\hline Scots pine $\log (1982)^{\mathrm{a}}$ & 52 & 623 & 0.06 & 0.59 & 7.53 & 0.048 \\
\hline $\log +30$ males +30 females $^{\mathrm{a}}$ & 52 & 774 & 0.06 & 0.65 & 7.53 & 0.059 \\
\hline$(+)-3$-Carene $e^{a}$ & 7 & 48 & 0.06 & 0.44 & 7.53 & 0.027 \\
\hline$(+)-\alpha$-Pinene ${ }^{a}$ & 7 & 60 & 0.06 & 0.50 & 7.53 & 0.034 \\
\hline$(-)-\alpha$-Pinene $e^{a}$ & 7 & 79 & 0.06 & 0.57 & 7.53 & 0.045 \\
\hline Terpinolene $^{\mathrm{a}}$ & 7 & 104 & 0.06 & 0.65 & 7.53 & 0.059 \\
\hline Scots pine $\log (1983)^{\mathrm{a}}$ & 7 & 256 & 0.06 & 1.02 & 7.53 & 0.146 \\
\hline April 15 , Monoterpenes ${ }^{\mathrm{b}}$ & 2.33 & 27 & 0.09 & 0.58 & 7.53 & 0.069 \\
\hline April 21, Monoterpenes ${ }^{\mathrm{b}}$ & 1 & 19 & 0.09 & 0.74 & 7.53 & 0.114 \\
\hline \multicolumn{7}{|l|}{ Ips typographus } \\
\hline High release pheromone ${ }^{c}$ & 6 & 753 & 0.06 & 1.90 & 6.9 & 0.546 \\
\hline Medium release pheromone ${ }^{\mathrm{d}}$ & 7 & 80 & 0.06 & 0.57 & 6.9 & 0.050 \\
\hline May 17, Pheromone ${ }^{\mathrm{e}}$ & 5.67 & 194 & 0.09 & 0.99 & 6.9 & 0.223 \\
\hline May 19, Pheromone $\mathrm{e}^{\mathrm{e}}$ & 1.33 & 18 & 0.09 & 0.62 & 6.9 & 0.088 \\
\hline May 20, Pheromone $\mathrm{e}^{\mathrm{e}}$ & 16.67 & 269 & 0.09 & 0.67 & 6.9 & 0.105 \\
\hline May 21, Pheromone $e^{\mathrm{e}}$ & 7.5 & 44 & 0.09 & 0.41 & 6.9 & 0.038 \\
\hline May 22, Pheromone $\mathrm{e}^{\mathrm{e}}$ & 8.5 & 215 & 0.09 & 0.85 & 6.9 & 0.165 \\
\hline
\end{tabular}

${ }^{a}$ Released about $30 \mathrm{mg}$ each compound per day; Scots pine, Pinus sylvestris L.; Byers et al. 1985.

${ }^{\mathrm{b}}$ Released about 10-20 mg/day of (+)- $\alpha$-pinene, $(-)$ - $\alpha$-pinene, and (+)-3-carene, and 3-5 mg/day of terpinolene; Byers et al. 1989.

${ }^{\mathrm{c}}$ High release of $57 \mathrm{mg}$ 2-methyl-3-buten-2-ol (MB) per day and $1 \mathrm{mg}(1 \mathrm{~S}, 4 \mathrm{~S}, 5 \mathrm{~S})$-cis-verbenol (cV) per day; Schlyter et al. 1987.

${ }^{\mathrm{d}}$ Medium release: $5.8 \mathrm{mg}$ MB per day and $1 \mathrm{mg} \mathrm{cV}$ per day; Schlyter et al. 1987.

${ }^{\mathrm{e}}$ Byers et al. 1989, medium release $\mathrm{MB}$ and $\mathrm{cV}$.

EAR and estimated $F_{\mathrm{L}}$. However, the $\mathrm{EAR}_{\mathrm{c}}$ can be larger than the EAR (Fig. 4), where both the $F_{\mathrm{L}}$ and the size of the $\mathrm{EAR}$ as a function of $\mathrm{EAR}^{2}$ affect the $\mathrm{EAR}_{\mathrm{c}}$.

The $\mathrm{SD}^{\circ}$ of turning angles usually does not affect encounter rates of insects with mates, host plants, or pheromone traps because the distances of insect search are far greater than distances to these objects at natural densities (Byers 1991, 2007). However, the $\mathrm{SD}^{\circ}$ does influence the encounter rate of insects that must travel relatively far in proportion to their allotted search distance to encounter an object at low density (Table 2). Surprisingly, a straight path $\left(\mathrm{SD}^{\circ}=0^{\circ}\right)$ caused insects to less often encounter an object than slightly more sinuous tracks $\left(\mathrm{SD}^{\circ}=5^{\circ}\right)$, while highly sinuous tracks (e.g., $\mathrm{SD}^{\circ}=30^{\circ}$ ) caused significantly fewer encounters. Short travel distances did not cause many encounters when insects began anywhere at random. This was because many insects could simply not reach the single object no matter how they traveled, as their search distance was less than their initial distance from the object. At larger search distances, insects could intercept the object by going straight but would have only one chance that was proportional to the object's diameter and initial distance because usually the insect could not return once it "missed" the object (only if meeting area's boundary). However, with a slightly more sinuous path, the insect had the same probability of intercepting the object, but there was an additional small probability that it could miss and then return to find the object due to the ability to turn $\left(\mathrm{SD}^{\circ}>0^{\circ}\right)$. At still higher $\mathrm{SD}^{\circ}$, many turns would tend to prevent many insects placed relatively far from the object from reaching the object, even though a few placed nearer the object could turn back and have one or more chances of interception. This means that predators and parasitoids that land on a leaf and search for insect hosts would benefit if they evolved a small but sufficient $\mathrm{SD}^{\circ}$ of about $5^{\circ}$ to cause more frequent host encounters than if they used a straight path or a highly sinuous path.

Estimation of the mean flight height and SD is done easily from either proportions or numbers caught on trap heights, although rarely are they calculated. Appropriate calculation of the SD assumes that the distribution is approximately normal and that catch does not continue to increase with height. The number of trap levels increases the accuracy and confidence of the calculated values. The type of traps used to monitor flight height should not matter as long as they are the same and catch a correct proportion of flying insects at the respective heights. However, many previous studies (Table 3 ) have not used passive traps but rather attractive traps (yellow color, ultraviolet lights, and sex/aggregation pheromone) that might alter the natural flight patterns. For example, Byers et al. (1989) found that sticky traps baited with aggregation pheromone or host plant monoterpenes altered the pattern of catch with height for two 
species of bark beetle compared to passive sticky traps. The mean flight height for I. typographus on passive traps was $4.63 \pm 2.75( \pm \mathrm{SD})$ and $F_{\mathrm{L}}=6.89$, while for the pine shoot beetle, Tomicus piniperda (L.), mean height was $5.98 \pm 3.00$ and $F_{\mathrm{L}}=7.52$. However, when aggregation pheromone was released at each height, I. typographus had a mean flight height of only $1.50 \pm 1.63$ and $F_{\mathrm{L}}=4.08(N=740)$, while $T$. piniperda attraction to host tree monoterpenes altered its mean flight height to $2.90 \pm 2.77$ and $F_{\mathrm{L}}=6.95(N=48)$. An estimation of the EAR from published results is usually not possible because (a) few studies have used unattractive sticky traps to intercept flying insects in comparison with attractive traps, or (b) the blank traps did not catch insects. For example, most moth pheromone studies (Pherobase: ElSayed 2007) have used traps where moths must enter to be caught (e.g., Delta traps), and so few were caught on blank traps (causing the EAR to be undefined).

The $\mathrm{EAR}_{\mathrm{c}}$ can be used to predict mating disruption and mass trapping with competitive attraction and camouflage by modeling male moth search, female calling, moth and dispenser densities, and $\mathrm{EAR}_{\mathrm{c}}$ of females and dispensers (Byers 2007, unpublished). However, many of these parameters are difficult to quantify in nature, such as moth density and male search distance. Other parameters, although usually not measured, can be estimated more easily such as EAR of females and dispensers by using catch ratios on sticky traps and converting to $\mathrm{EAR}_{\mathrm{c}}$ with $F_{\mathrm{L}}$ estimated from sticky trap catches at fixed heights. The estimated $\mathrm{EAR}_{\mathrm{c}}$ of $0.82 \mathrm{~m}$ discussed above for a standard I. typographus trap can be used in the model of Byers (2007) with no competition (female $\mathrm{EAR}=0$ ) to determine the catch of these bark beetles. For example, if five of these traps are placed in a $200 \times 200 \mathrm{~m}$ Norway spruce forest with 360 beetles (Byers et al. 1989) flying at $2 \mathrm{~m} / \mathrm{s}$ for up to $6 \mathrm{~km}$, then $99 \%$ are expected to be caught. This assumes there are no pheromone sources of competitive attraction such as might occur shortly after flight initiation in the spring. Models can predict mass trapping and mating disruption outcomes correctly only when the relevant parameters are known with good precision. Otherwise, models are still useful to gain better understanding of the effects of the parameters on decisions regarding control and the likely efficacy of deploying pheromone dispensers of various numbers and $\mathrm{EAR}_{\mathrm{c}}$.

Acknowledgments In addition to the editors, I thank Ashraf ElSayed, Steve Naranjo, and two anonymous reviewers for their reviews of the manuscript.

\section{References}

Atkinson, T. H., Foltz, J. L., and Connor, M. D. 1988. Flight patterns of phloem- and wood-boring Coleoptera (Scolytidae, Platypodidae, Curculionidae, Buprestidae, Cerambycidae) in a north Florida slash pine plantation. Environ. Entomol. 17:259265.

BAKER, T. C., and ROELOFS, W. L. 1981. Initiation and termination of oriental fruit moth male response to pheromone concentrations in the field. Environ. Entomol. 10:211-218.

BAKER, T. C., HANSSON, B. S., LÖFSTEDT, C., and LÖFQVist, J. 1989. Adaptation of male moth antennal neurons in a pheromone plume is associated with cessation of pheromone-mediated flight. Chem. Senses 14:439-448.

Baker, T. C., FAdamiro, H., and Cossé, A. A. 1998. Fine-grained resolution of closely spaced odor strands by flying male moths. Nature 393:530.

BARTELL, R. J. 1982. Mechanisms of communication disruption by pheromones in control of Lepidoptera: a review. Physiol. Entomol. 7:353-364.

BARTEll, R. J., and Roelofs, W. L. 1973. Inhibition of sexual response in males of the moth Argyrotaenia velutinana by brief exposures to synthetic pheromone or its geometric isomer. $J$. Insect Physiol. 19:655-661.

Boiteau, G., Bousquet, Y., and Osborn, W. 2000. Vertical and temporal distribution of Carabidae and Elateridae in flight above an agricultural landscape. Environ. Entomol. 29:1157-1163.

Bossert, W. H., and Wilson, E. O. 1963. The analysis of olfactory communication among animals. J. Theor. Biol. 5:443-469.

Branco, M., Jactel, H., Franco, J. C., and Mendel, Z. 2006. Modelling response of insect trap captures to pheromone dose. Ecol. Model. 197:247-257.

BYERS, J. A. 1987. Interactions of pheromone component odor plumes of western pine beetle. J. Chem. Ecol. 13:2143-2157.

Byers, J. A. 1991. Simulation of mate-finding behaviour of pine shoot beetles, Tomicus piniperda. Anim. Behav. 41:649-660.

BYERS, J. A. 1993a. Simulation and equation models of insect population control by pheromone-baited traps. J. Chem. Ecol. 19:1939-1956.

Byers, J. A. 1993b. Orientation of bark beetles Pityogenes chalcographus and Ips typographus to pheromone-baited puddle traps placed in grids: A new trap for control of scolytids. J. Chem. Ecol. 19:2297-2316.

BYERS, J. A. 1996a. An encounter rate model for bark beetle populations searching at random for susceptible host trees. Ecol. Model. 91:57-66.

BYERS, J. A. 1996b. Temporal clumping of bark beetle arrival at pheromone traps: Modeling anemotaxis in chaotic plumes. $J$. Chem. Ecol. 22:2133-2155.

BYERS, J. A. 1999. Effects of attraction radius and flight paths on catch of scolytid beetles dispersing outward through rings of pheromone traps. J. Chem. Ecol. 25:985-1005.

Byers, J. A. 2001. Correlated random walk equations of animal dispersal resolved by simulation. Ecology 82:1680-1690.

BYERS, J. A. 2007. Simulation of mating disruption and mass trapping with competitive attraction and camouflage. Environ. Entomol. 36:1328-1338.

Byers, J. A., Anderbrant, O., and LöfQvist, J. 1989. Effective attraction radius: A method for comparing species attractants and determining densities of flying insects. J. Chem. Ecol. 15:749765.

Byers, J. A., Lanne, B. S., Löfqvist, J., Schlyter, F., and BERGSTRÖM, G. 1985. Olfactory recognition of host-tree susceptibility by pine shoot beetles. Naturwissenschaften 72:324-326.

CARDÉ, R. T. 1990. Principles of mating disruption, pp. 47-71, in R. L. Ridgway, and R. M. Silverstein (eds.). Behavior-Modifying Chemicals for Pest Management: Applications of Pheromones and other Attractants. Marcel Dekker, New York.

CARDÉ, R. T., and Minks, A. K. 1995. Control of moth pests by mating disruption: successes and constraints. Annu. Rev. Entomol. 40:559-585. 
CHANDLER, L. D. 1985. Flight activity of Liriomyza trifolii (Diptera: Agromyzidae) in relationship to placement of yellow traps in bell pepper. J. Econ. Entomol. 78:825-828.

EL-SAYED, A. M. 2007. The Pherobase: database of insect pheromones and semiochemicals. (http://www.pherobase.com).

El-SaYed, A. M., Suckling, D. M., Wearing, C. H., and Byers, J. A. 2006. Potential of mass trapping for long-term pest management and eradication of invasive species. J. Econ. Entomol. 99:1550-1564.

ELKINTON, J. S., and CARDÉ, R. T. 1984. Odor dispersion, pp. 73-91, in W. J. Bell, and R. T. Cardé (eds.). Chemical Ecology of Insects. Sinauer Associates, Sunderland.

ElKinton, J. S., CARDÉ, R. T., and MASON, C. J. 1984. Evaluation of time-averaged dispersion models for estimating pheromone concentration in a deciduous forest. J. Chem. Ecol. 10:1081-1108.

Fares, Y., Sharpe, P. J. H., and Magnuson, C. E. 1980. Pheromone dispersion in forests. J. Theor. Biol. 84:335-359.

Holling, C. S. 1959. Some characteristics of simple types of predation and parasitism. Can. Entomol. 91:385-398.

InTACHAT, J., and HollowaY, J. D. 2000. Is there stratification in diversity or preferred flight height of geometroid moths in Malaysian lowland tropical forest? Biodiv. Conserv. 9:14171439.

ISAACS, R., and BYRNE, D. N. 1998. Aerial distribution, flight behaviour and eggload: their inter-relationship during dispersal by the sweetpotato whitefly. J. Anim. Ecol. 67:741-750.

IVBIJARO, M. F., and DARAMOLA, A. M. 1977. Flight activity of the adult kola weevil, Balanogastris kolae (Coleoptera: Curculionidae) in relation to infestation. Entomol. Exp. Appl. 22:203-207.

Joron, M. 2005. Polymorphic mimicry, microhabitat use, and sexspecific behaviour. J. Evol. Biol. 18:547-556.

JudD, G. J. R., GARdiner, M. G. T., Delury, N. C., and KARG, G. 2005. Reduced antennal sensitivity, behavioural response, and attraction of male codling moths, Cydia pomonella, to their pheromone $(E, E)-8,10$-dodecadien-1-ol following various preexposure regimes. Entomol. Exp. Appl. 114:65-78.

KUENEN, L. P. S., and BAKER, T. C. 1981. Habituation versus sensory adaptation as the cause of reduced attraction following pulsed and constant sex pheromone pre-exposure in Trichoplusia ni. J. Insect Physiol. 27:721-726.

LAMB, R. J. 1983. Phenology of flea beetle (Coleoptera: Chrysomelidae) flight in relation to their invasion of canola fields in Manitoba. Can. Entomol. 115:1493-1502.

Mankin, R. W., Vick, K. W., MaYer, M. S., Coffelt, J. A., and CALlAHAN, P. S. 1980. Models for dispersal of vapors in open and confined spaces: Applications to sex pheromone trapping in a warehouse. J. Chem. Ecol. 6:929-950.

MASON, L. J., JANSSON, R. K., and HEATH, R. R. 1990. Sampling range of male sweetpotato weevils (Cylas formicarius elegantulus) (Summers) (Coleoptera: Curculionidae) to pheromone traps: Influence of pheromone dosage and lure age. J. Chem. Ecol. 16:2493-2502.

MC CALL, R. B. 1970. Fundamental Statistics for Psychology. Harcourt, Brace and World, New York.

Mc Clendon, R. W., Mitchell, E. B., Jones, J. W., Mc Kinion, J. M., and HARDEE, D. D. 1976. Computer simulation of pheromone trapping systems as applied to boll weevil population suppression: a theoretical example. Environ. Entomol. 5:799-806.

MessinA, F. J. 1982. Timing of dispersal and ovarian development in goldenrod leaf beetles Trirhabda virgata and T. borealis. Ann. Entomol. Soc. Am. 74:78-83.

MeYer, J. R., and Colvin, S. A. 1985. Diel periodicity and trap bias in sticky trap sampling of sharpnosed leafhopper populations. $J$. Entomol. Sci. 20:237-243.

MeYerdirK, D. E., and Moreno, D. S. 1984. Flight behavior and color-trap preference of Parabemisis myricae (Kuwana) (Homoptera: Aleyrodidae) in a citrus orchard. Environ. Entomol. $13: 167-170$
MeyerdirK, D. E., and OldField, G. N. 1985. Evaluation of trap color and height placement for monitoring Circulifer tenellus (Baker)(Homoptera: Cicadellidae). Can. Entomol. 117:505-511.

Miller, J. R., Gut, L. J., De Lame, F. M., and Stelinski, L. L. 2006a. Differentiation of competitive vs. non-competitive mechanisms mediating disruption of moth sexual communication by point sources of sex pheromone (Part 1): Theory. J. Chem. Ecol. 32:2089-2114.

Miller, J. R., Gut, L. J., DE LAme, F. M., and Stelinski, L. L. 2006b. Differentiation of competitive vs. non-competitive mechanisms mediating disruption of moth sexual communication by point sources of sex pheromone (Part 2): Case Studies. J. Chem. Ecol. 32:2115-2143.

NAKAMURA, K., and KAWASAKI, K. 1977. The active space of the Spodoptera litura (F.) sex pheromone and the pheromone component determining this space. Appl. Entomol. Zool. 12:162-177.

Östrand, F., and ANDERBRANT, O. 2003. From where are insects recruited? A new model to interpret catches of attractive traps. Agricul. Forest Entomol. 5:163-171.

PeARSALl, I. A., and MYers, J. H. 2001. Spatial and temporal patterns of dispersal of western flower thrips (Thysanoptera: Thripidae) in nectarine orchards in British Columbia. J. Econ. Entomol. 94:831-843.

Rumbo, E. R., and Vickers, R. A. 1997. Prolonged adaptation as possible mating disruption mechanism in oriental fruit moth, Cydia (=Grapholita) molesta. J. Chem. Ecol. 23:445-457.

Rummel, D. R., JoRDAN, L. B., White, J. R., and WADE, L. J. 1977. Seasonal variation in the height of boll weevil flight. Environ. Entomol. 6:674-678.

SChlyter, F., BYERS, J. A., and LÖFQVIST, J. 1987. Attraction to pheromone sources of different quantity, quality, and spacing: Density-regulation mechanisms in bark beetle Ips typographus. J. Chem. Ecol. 13:1503-1523.

SHOREY, H. H. 1977. Manipulation of insect pests of agricultural crops, pp. 353-367, in H. H. Shorey, and J. J. McKelvey Jr. (eds.). Chemical Control of Insect Behaviour: Theory and Application. Wiley, New York.

Sower, L. L., Gaston, L. K., and Shorey, H. H. 1971. Sex pheromones of noctuid moths. XXVI. Female release rate, male response threshold, and communication distance for Trichoplusia ni. Ann. Ent. Soc. Am. 64:1448-1456.

StewART, S. D., and GAYLOR, M. J. 1991. Age, sex, and reproductive status of the tarnished plant bug (Heteroptera: Miridae) colonizing mustard. Environ. Entomol. 20:1387-1392.

StONE, J. D. 1986. Time and height of flight of adults of white grubs (Coleoptera: Scarabaeidae) in the southwestern United States. Environ. Entomol. 15:194-197.

SutTON, O. G. 1953. Micrometeorology. McGraw-Hill, New York.

TURChIN, P. 1998. Quantitative Analysis of Movement. Sinauer Associates, Sunderland.

Turchin, P., and OdendaAL, F. J. 1996. Measuring the effective sampling area of a pheromone trap for monitoring population density of southern pine beetle (Coleoptera: Scolytidae). Environ. Entomol. 25:582-588.

VAnwoerkom, G. J., Turpin, F. T., and BArrett, J. R. Jr. 1983. Wind effect on western corn rootworm (Coleoptera: Chrysomelidae) flight behavior. Environ. Entomol. 12:196-200.

WAll, C., and Perry, J. N. 1987. Range of action of moth sexattractant sources. Entomol. Exp. Appl. 44:5-14.

Weber, D. C., Robbins, P. S., and Averill, A. L. 2005. Hoplia equina (Coleoptera: Scarabaeidae) and nontarget capture using 2tetradecanone-baited traps. Environ. Entomol. 34:158-163.

WORNER, S. P. 1991. Use of models in applied entomology: the need for perspective. Environ. Entomol. 20:768-773.

ZOLUBAS, P., and BYERS, J. A. 1995. Recapture of dispersing bark beetle, Ips typographus L. (Col., Scolytidae) in pheromonebaited traps: regression models. J. Appl. Entomol. 119:285-289. 